\title{
ESTUDO QUÍMICO DE LODO GERADO NUM SISTEMA ANAERÓBICO DE TRATAMENTO DE EFLUENTES DE ORIGEM RESIDENCIAL
}

\author{
Vagner Guedes, Wilson Costa, Ariane Caroline Ribicki. \\ Universidade Estadual de Ponta Grossa (UEPG), CEP - 84030-900, Ponta Grossa, PR, Brasil.
}

E-mail: wcosta@uepg.br

Recebido em: $22 / 09 / 2014$ Aceito em 13/07/2015

\section{RESUMO}

O tratamento de efluentes de origem residencial é geralmente realizado em Estações de Tratamento de Efluentes (ETEs), por processos biológicos aeróbios e ou anaeróbios que apresentam dispositivos de ordem variável e geram resíduos definidos como sólidos segundo a ABNT 10004/2004. Um dos dispositivos que pode estar presente numa ETE que utiliza processo anaeróbio é o reator de manta de lodo. O objetivo deste trabalho foi de avaliar quimicamente a composição do lodo gerado num destes reatores através da fluorescência de raios X, carbono orgânico (CO), matéria orgânica (MO), nitrogênio total Kjeldahl (NTK), relação C/N, capacidade de troca catiônica efetiva (CTC), relação CTC/CO, potássio (K), fósforo orgânico (PO), fósforo mineral (PM) e determinar a concentração de $\mathrm{Cr}, \mathrm{Cu}, \mathrm{Ni}, \mathrm{Ag}, \mathrm{Fe}, \mathrm{Mn}, \mathrm{Zn}, \mathrm{Pb}, \mathrm{Cd}$ e Ba nos extratos obtidos através do método de Tessier. Através da fluorescência de raios X, observou-se que a somatória das porcentagens dos elementos Al, Si, Fe, S, Ca, P, Ti, K e Zn está próxima de $99 \%$. Que os valores médios da MO, NTK e CTC são respectivamente 20,2\%, 0,64 \% e 19,6 cmolc kg-1, e que a disposição desse material no meio ambiente pode ser associada a algum risco devido às concentrações de ferro, manganês, zinco e cádmio, em presença de um redutor, ferro em presença de um oxidante e manganês em presença de $\mathrm{pH}=5$ estarem acima do valor máximo permitido (VMP) da Resolução CONAMA 430 /11.

Palavras chave: Lodos de efluentes, lixiviação de metais.

\section{Introdução}

Os processos de tratamento de águas residuárias são divididos inicialmente em dois grandes grupos, os biológicos e os físico-químicos. A utilização de um ou de outro, ou mesmo a combinação de ambos, depende das características do efluente a ser tratado, da área disponível para montagem do sistema de tratamento e do nível de depuração que se deseja atingir [1].

Os processos biológicos foram concebidos para serem aplicados na remoção de material orgânico carbonáceo, nitrificação, desnitrificação, remoção do fósforo e estabilização do lodo gerado no sistema primário e secundário, possibilitando assim a correção das características indesejáveis do esgoto e a sua disposição final, de acordo com as regras e critérios definidos pela legislação ambiental [2].

No Brasil, os sistemas anaeróbios encontram uma grande aplicabilidade. As diversas características favoráveis destes sistemas, como o baixo custo, simplicidade operacional e baixa produção de sólidos, aliadas às condições ambientais, onde há a predominância de elevadas temperaturas, têm contribuído para a colocação dos sistemas anaeróbios de tratamento de esgotos, em posição de destaque, particularmente os reatores de manta de lodo, que consiste de um fluxo ascendente do efluente através de um leito de lodo biológico denso e de elevada atividade microbiana [3].

Nestes reatores de manta de lodo, o fluxo do líquido é ascendente. A parte superior do reator é dividida nas zonas de sedimentação e de coleta de gás. A zona de sedimentação permite a saída do efluente clarificado e o retorno dos sólidos (biomassa) ao sistema, aumentando sua concentração no reator [4].

À medida que o manto de lodo vai se tornando mais denso ele passa a funcionar como um filtro, retendo também os sólidos de menores dimensões que, nos processos clássicos de decantação, dificilmente são removidos. A matéria orgânica contida no efluente ficará retida no manto de lodo devido às baixas velocidades ascensionais, onde os sólidos sedimentáveis encontram o equilíbrio entre a força ascensional e a força de gravidade. O material biodegradável que ficou retido no manto de lodo será degradado e estabilizado através da atividade metabólica das bactérias. As bactérias transformarão a matéria orgânica em suspensão e/ou dissolvidas em produtos estáveis como a água e biogás [5].

Os gases seguirão para o gasômetro, localizado na parte superior interna do reator de onde poderão ser descartados para a atmosfera ou captados para fins energéticos. A parte sólida (flocos de lodos) arrastada pelas bolhas de gás se desprende das mesmas na parte superior e o lodo volta para o manto de lodo. O líquido segue para o decantador periférico, onde as partículas que são arrastadas pelo fluxo são decantadas e retornam ao manto de lodo [6].

Um destino adequado deve ser dado a esse resíduo e, para tal, algumas alternativas têm sido propostas. A disposição em aterros sanitários é uma opção aceitável tecnicamente, porém apresenta custo de manutenção muito elevado; o despejo nos oceanos, rios e lagos é prática proibida por lei nos Estados Unidos por causar sérios danos ao ambiente; a incineração é uma alternativa prática mas, 
não econômica, pois gera gases poluentes para a atmosfera [7].

De composição bastante variada em consequiência de peculiaridades regionais e dos processos em que é gerado, o lodo de esgoto contém considerável percentual de matéria orgânica e elementos essenciais às plantas, podendo substituir, ainda que parcialmente, os fertilizantes industriais, desempenhando importante papel na produção agrícola e na manutenção da fertilidade do solo [8].

Muitos trabalhos existentes na literatura estão relacionados ao estudo das alterações das propriedades químicas do solo, após o aporte de lodo oriundo do tratamento de efluentes de origem residencial $[9,10,11]$.

O objetivo deste trabalho é de caracterizar quimicamente o lodo gerado num reator de manta de lodo e determinar em quais condições ocorre a lixiviação de determinados metais pesados em concentrações acima daquelas estabelecidas pela Resolução CONAMA 430/11 [12].

\section{Parte Experimental}

\subsection{Coletas e tratamento das amostras}

As coletas foram realizadas no período de junho de 2011 a julho de 2012, nas dez descargas de um reator de manta de lodo instalado na região sul do Brasil que recebe efluente de origem residencial numa vazão de $20 \mathrm{~L} \mathrm{~s}^{-1}$. A seguir, as amostras foram secas a $40{ }^{\circ} \mathrm{C}$ até massa constante, trituradas em almofariz e pistilo de ágata e peneiradas em malha de $0,105 \mathrm{~mm}$ para serem submetidas a caracterização química e avaliação da mobilidade de determinados metais.

\subsection{Caracterização química}

\section{Fluorescência de raios $\mathrm{X}$}

Utilizou-se o espectrômetro de Fluorescência de raios X e energia dispersiva da marca Shimadzu (EDX-720). $\mathrm{O}$ espectrômetro foi operado a $50 \mathrm{kV}$, alvo de $\mathrm{Rh}, 10 \mathrm{~mA}$, Collimator: $10 \mathrm{~mm}$, Detector: $\mathrm{Si}$ (Li) semiconductor detector, resolução de energia em aproximadamente $155 \mathrm{eV}$ e tempo de análise $100 \mathrm{~s}$.

$\mathrm{pH}$

Realizada potenciometricamente em suspensão solo-solução de $\mathrm{CaCl}_{2}$ [13].

\section{Carbônico orgânico (CO), Matéria orgânica (MO)}

O carbono orgânico foi determinado pelo método de Walkley \& Black. O teor de MO foi calculada considerando ser constituída em média de 52 a $58 \%$ de carbono [14].

\section{Nitrogênio total Kjeldahl (NTK), Relação C/N}

Para a determinação do nitrogênio total Kjeldahl (orgânico e amoniacal) foi utilizada a técnica de Kjeldahl [13]. A relação $\mathrm{C} / \mathrm{N}$ foi calculada dividindo as concentrações de carbono orgânico pela de NTK [15].

\section{CTC efetiva, Relação CTC/CO}

Foi calculada pela soma dos cátions metálicos totais trocáveis (SB), que são $\mathrm{Ca}^{2+}, \mathrm{Mg}^{2+}, \mathrm{K}^{+}, \mathrm{Na}^{+}$(bases), com a acidez trocável (AT), que corresponde à somatória das concentrações de $\mathrm{H}^{+}$e $\mathrm{Al}^{3+}$, segundo procedimentos descritos por Cotta e colaboradores [16]. A relação CTC/CO foi calculada dividindo os valores da CTC pelos valores das concentrações de carbono orgânico [7].

Potássio $\left(\mathrm{K}^{+}\right)$.

Determinado por espectrometria de emissão pela chama [13]. O extrator utilizado foi o de Mehlich que consiste de uma mistura de $\mathrm{HCl} / \mathrm{H}_{2} \mathrm{SO}_{4}$ [17].

Fósforo orgânico (PO) e Fósforo mineral (PM)

A extração foi efetuada segundo procedimento descrito por Jackson [18]. A determinação foi através da espectrofotometria na região do visível [19].

\subsection{Avaliação da mobilidade}

Para a avaliação da mobilidade dos metais foi realizada a extração sequencial segundo método de Tessier e colaboradores [20], conduzida em triplicata para $1 \mathrm{~g}$ de cada amostra. Este método é o mais citado e utilizado na literatura entre todos os métodos de extração sequencial e foi criado para a determinação de metais pesados em sedimentos [21].

As soluções empregadas são reagentes seletivos, isto é, capazes de extrair para a fase líquida os elementos presentes em tipos específicos de fases ou frações, por reações de troca iônica, oxi-redução e dissolução [22].

Nesta extração, os metais lixiviados estão nas formas em que podem ser removidos em $\mathrm{pH}=8,0$ com acetato de sódio; $\mathrm{pH}=5,0$ utilizando acetato de sódio/ácido acético; aplicação de um redutor (R) que aqui é representado por cloreto de hidroxilamina/ácido acético e ação de um oxidante $(\mathrm{O})$, que neste método é uma mistura de $\mathrm{HNO}_{3} / \mathrm{H}_{2} \mathrm{O}_{2}$. A forma residual (R) é obtida quando a amostra recebe um tratamento agressivo com ácidos fluorídrico e perclórico [20].

As concentrações dos metais: $\mathrm{Cr}, \mathrm{Cu}, \mathrm{Ni}, \mathrm{Ag}, \mathrm{Fe}$, $\mathrm{Mn}, \mathrm{Zn}, \mathrm{Pb}, \mathrm{Cd}$ e $\mathrm{Ba}$ foram determinados nestas frações por espectroscopia de absorção atômica, com atomização por chama utilizando o aparelho Varian Spectra AAS - 240FS.

\section{Resultados e discussões}

\section{Fluorescência de raios $\mathrm{X}$}

$\mathrm{Na}$ Tabela 1, encontram-se as concentrações dos elementos determinados por fluorescência de raios $\mathrm{X}$, com as respectivas médias e desvios padrões. 
Tabela 1. Concentrações dos elementos em porcentagem determinados por Fluorescência de raios X com as respectivas médias e desvios padrões (DP).

\begin{tabular}{|c|c|c|c|c|c|c|c|c|c|c|c|c|}
\hline \multirow{3}{*}{$\mathrm{E}$} & \multicolumn{12}{|c|}{ Amostras } \\
\hline & 1 & 2 & 3 & 4 & 5 & 6 & 7 & 8 & 9 & 10 & M & $\mathrm{DP}$ \\
\hline & & & & & & $\%$ & & & & & & \\
\hline $\mathrm{Al}$ & 26,4 & 26,5 & 27,4 & 25,2 & 26,6 & 25,6 & 25,1 & 25,9 & 25,0 & 26,1 & 26,0 & 0,83 \\
\hline $\mathrm{Si}$ & 26,2 & 25,9 & 25,6 & 24,9 & 25,8 & 25,2 & 26,1 & 25,3 & 24,6 & 26,3 & 25,6 & 0,78 \\
\hline $\mathrm{Fe}$ & 22,3 & 21,8 & 20,5 & 21,6 & 20,6 & 21,1 & 22,0 & 21,7 & 21,8 & 21,3 & 21,5 & 0,59 \\
\hline$S$ & 9,5 & 9,9 & 10,1 & 11,8 & 11,0 & 10,5 & 10,0 & 10,3 & 11,6 & 10,5 & 10,5 & 0,74 \\
\hline $\mathrm{Ca}$ & 5,4 & 5,2 & 5,9 & 6,6 & 6,0 & 7,3 & 7,4 & 6,9 & 6,7 & 5,5 & 6,3 & 0,80 \\
\hline $\mathrm{P}$ & 4,6 & 4,3 & 4,6 & 4,3 & 4,3 & 4,4 & 3.9 & 4,2 & 4,3 & 4,5 & 4,3 & 0,21 \\
\hline $\mathrm{Ti}$ & 2,5 & 2,5 & 2,5 & 2,4 & 2,5 & 2,6 & 2,5 & 2,5 & 2,6 & 2,5 & 2,5 & 0,06 \\
\hline $\mathrm{K}$ & 2,2 & 2,2 & 2,4 & 2,2 & 2,2 & 2,2 & 1,9 & 2,1 & 2,4 & 2,2 & 2,2 & 0,14 \\
\hline $\mathrm{Zn}$ & 0,5 & 0,6 & 0,6 & 0,5 & 0,5 & 0,6 & 0,5 & 0,5 & 0,5 & 0,5 & 0,57 & 0,06 \\
\hline Mn & 0,2 & 0,2 & 0,2 & 0,2 & 0,2 & 0,2 & 0,2 & 0,2 & 0,2 & 0,2 & 0,2 & 0,00 \\
\hline $\mathrm{Zr}$ & 0,1 & 0,1 & 0,1 & 0,1 & 0,1 & 0,1 & 0,1 & 0,1 & 0,1 & 0,1 & 0,1 & 0,00 \\
\hline $\mathrm{Cu}$ & 0,1 & 0,1 & 0,1 & 0,1 & 0,1 & 0,1 & 0,1 & 0,1 & 0,1 & 0,1 & 0,1 & 0,00 \\
\hline V & 0,1 & - & - & 0,1 & 0,1 & - & 0,1 & 0,1 & 0,1 & 0,1 & 0,07 & 0,05 \\
\hline $\mathrm{Cr}$ & - & - & - & - & - & 0,1 & 0,1 & 0,1 & - & 0,1 & 0,04 & 0,06 \\
\hline $\mathrm{Ba}$ & - & 0,7 & - & - & - & - & - & - & - & - & 0,07 & 0,24 \\
\hline
\end{tabular}

Observou-se que os elementos mais representativos são: $\mathrm{Al}, \mathrm{Si}, \mathrm{Fe}, \mathrm{S}, \mathrm{Ca}, \mathrm{P}, \mathrm{Ti}$ e K. A soma da média das concentrações destes atinge o valor de 98,9 \%. Elementos como $\mathrm{Zn}, \mathrm{Mn}, \mathrm{Zr}, \mathrm{Cu}, \mathrm{V}, \mathrm{Cr}$ e Ba estão em concentrações muito baixas, e em algumas amostras, ausentes. Dos elementos mais tóxicos, aqueles que foram encontrados através desta técnica foram: $\mathrm{Zn}, \mathrm{Cu}, \mathrm{Cr}$ e $\mathrm{Ba}$.
$\mathrm{Na}$ Tabela 2 estão as variações das concentrações de Carbono Orgânico (CO), Matéria orgânica (MO), Nitrogênio Total Kjeldahl (NTK), Relação C/N, Capacidade de troca catiônica (CTC), Acidez trocável (AT), Soma das bases totais trocáveis (SB), relação CTC/CO com as respectivas médias e desvios padrões.

Tabela 2. Valores de CO, MO, NTK, relação C/N, CTC, AT, SB, relação CTC/CO com as respectivas médias e desvios padrões.

\begin{tabular}{ccccccccc}
\hline $\mathrm{A}$ & $\mathrm{CO}$ & $\mathrm{MO}$ & $\mathrm{NTK}$ & $\mathrm{C} / \mathrm{N}$ & $\mathrm{CTC}$ & $\mathrm{AT}$ & $\mathrm{SB}$ & $\mathrm{CTC} / \mathrm{CO}$ \\
$\mathrm{cmol}_{\mathrm{c}} \mathrm{kg}^{-1}$ & $\mathrm{cmol}_{\mathrm{c}} \mathrm{kg}^{-1} \mathrm{cmol}_{\mathrm{c}} \mathrm{kg}^{-1}$ & \\
\hline 1 & 9,0 & 15,5 & 0,43 & 20,4 & 17,9 & 1,93 & 15,97 & 238,6 \\
2 & 9,4 & 16,1 & 0,73 & 12,9 & 20,9 & 2,00 & 18,90 & 266,9 \\
3 & 11,6 & 20,0 & 0,64 & 18,2 & 18,8 & 1,56 & 17,24 & 193,8 \\
4 & 12,9 & 22,2 & 0,78 & 16,5 & 21,3 & 2,18 & 19,12 & 198,1 \\
5 & 11,5 & 19,8 & 0,50 & 23,0 & 19,6 & 1,67 & 17,93 & 204,6 \\
6 & 11,9 & 20,4 & 0,62 & 19,1 & 19,1 & 1,59 & 17,51 & 192,5 \\
7 & 12,4 & 21,4 & 0,74 & 16,8 & 18,7 & 1,76 & 16,94 & 181,6 \\
8 & 12,8 & 22,1 & 0,64 & 20,1 & 19,5 & 3,15 & 16,35 & 182,2 \\
9 & 11,8 & 19,3 & 0,57 & 20,8 & 18,9 & 2,49 & 16,41 & 192,3 \\
10 & 14,6 & 25,0 & 0,78 & 18,7 & 20,8 & 3,74 & 17,06 & 170,5 \\
M & 11,8 & 20,2 & 0,64 & 18,7 & 19,6 & 2,21 & 17,34 & 202,1 \\
DP & 1,6 & 2,8 & 0,35 & 2,8 & 1,1 & 0,66 & 1,07 & 29,1 \\
\hline
\end{tabular}




\section{Relações entre CO, MO e CTC}

O componente principal do esgoto é a matéria orgânica [23] que é formada basicamente por carbono. Com os dados presentes na Tabela 2, se observa que as concentrações médias de carbono orgânico e matéria orgânica encontradas nas amostras de lodo analisadas correspondem respectivamente a 11,8 e 20,2\%.

Encontrou-se trabalhos em que o foco está relacionado a alterações da composição do solo após aplicação de lodo de esgoto. A única informação referente a este composto é que se origina de ETES cujo tratamento é anaeróbico [24, 25, 26]. Nestes, são encontradas diversas análises de lodo com resultados divergentes aos presentes neste trabalho e isto pode estar relacionado a diferenças no que diz respeito a região onde ele é produzido, número de amostras analisadas, vazão e tipo de dispositivo anaeróbico utilizado.

A CTC atingiu um valor médio de 19,6 $\mathrm{cmol}_{\mathrm{c}} \mathrm{kg}^{-1}$, que é maior que as encontradas em trabalhos de solo $[8,27]$, bem inferior a de vermicomposto de esterco bovino [28] e próxima a de lodo de ETE de origem residencial em que não está definido se a origem é anaeróbica que utiliza reator de manta de lodo [7].

Na Figura 1, encontram-se as variações do CO, MO e CTC.

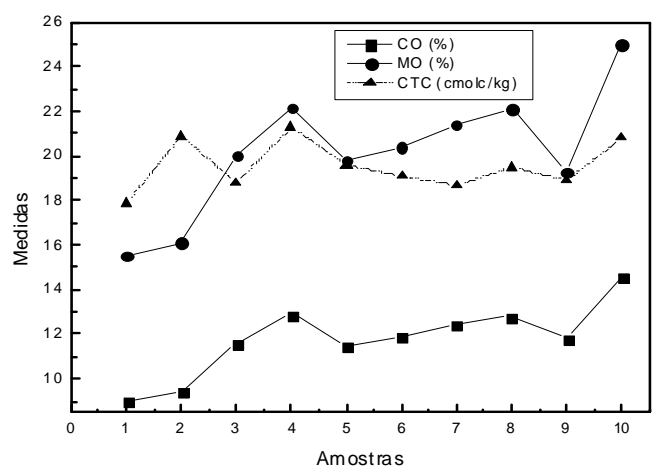

Figura 1. Variações de $\mathrm{CO}, \mathrm{MO}$ e CTC

No método utilizado para determinar $\mathrm{CO}$, faz-se uso de um oxidante que reage com o carbono e também com outras subtâncias redutoras que estiverem presentes. Para a matéria orgânica, considera-se que geralmente ela apresenta 52 a $58 \%$ de carbono [14], então, um aumento no teor de $\mathrm{CO}$ é acompanhado pela elevação na concentração de $\mathrm{MO}$ e isso pode ser evidenciado pela análise da Figura 1.

Valores de CTC acima de $5 \mathrm{cmolc} / \mathrm{kg}$, evidenciam uma alta capacidade de troca de cátions [29]. Os valores encontrados estão bem acima deste valor e isto pode ser atribuído as altas concentrações de matéria orgânica.

$\mathrm{Na}$ análise dos dados presentes na Figura 1, se observa em vários pontos que o aumento da CTC é acompanhado de uma elevação nas concentrações de CO. Nas amostras em que isso não ocorre, é porque, além do carbono, possivelmente outras espécies redutoras que podem estar presentes no lodo, como $\mathrm{Fe}^{2+}[30]$, também reagiram com o oxidante empregado na determinação do carbono orgânico [14].

\section{Relações entre CTC, AT e SB}

A CTC foi obtida pela somatória dos cátions metálicos totais trocáveis (SB), que são $\mathrm{Ca}^{2+}, \mathrm{Mg}^{2+}, \mathrm{K}^{+}, \mathrm{Na}^{+}$ (SB) com a acidez trocável (AT), que corresponde às concentrações de $\mathrm{H}^{+}$e $\mathrm{Al}^{3+}$. Pelos dados presentes na Tabela 2 , se observa que a SB é o parâmetro que exerceu a maior influência na CTC, correspondendo em média a aproximadamente $88,5 \%$ do valor encontrado.

Em trabalhos em que novamente não está definido se o lodo da ETE de origem residencial tem origem anaeróbica em reator de manta de lodo $[9,10]$, se observa que o aporte de quandidades crescentes deste material em solo é acompanhado da elevação da CTC e da contribuição da SB nos valores deste parâmetro.

Na Figura 2 se encontram as variações da CTC, AT e SB.

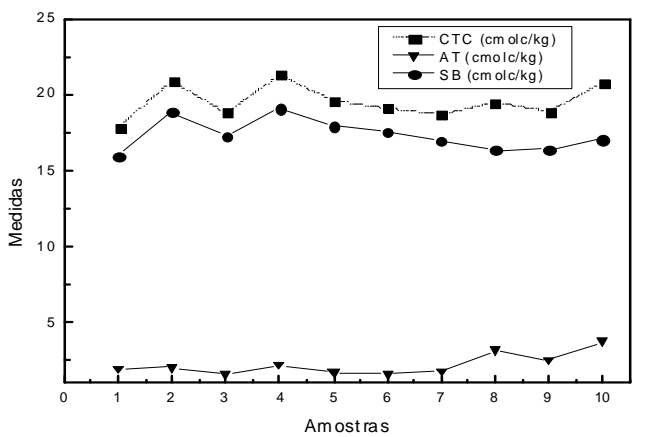

Figura 2. Variações de CTC, AT e CTC

Pela análise dos dados presentes na Figura 2, se observa a grande contribuição da SB nos valores da CTC e que geralmente as elevações nos valores deste parâmetro é acompanhado do aumento das concentrações da SB e AT.

\section{Relações entre NTK, CO, C/N, CTC/CO}

$\mathrm{O}$ Nitrogênio total Kjeldahl corresponde à somatória dos teores de nitrogênio orgânico e amoniacal. A concentração média deste parâmetro foi de $0,78 \%$ ou $7,8 \mathrm{~g} \mathrm{~kg}^{-1} \mathrm{e}$ a relação $\mathrm{C} / \mathrm{N}$ atingiu o valor médio de 18,7 (Tabela 2).

O nitrogênio é fundamental para que os microrganismos tenham o bom desempenho na degradação da $\mathrm{MO}$ e isto pode ser avaliado através da relação $\mathrm{C} / \mathrm{N}$. Uma redução deste parâmetro indica uma maior dificuldade na degradação.

A relação CTC/CO é um indicativo do grau de maturação e qualidade dos fertilizantes orgânicos e é considerada como mais apropriada que a relação $\mathrm{C} / \mathrm{N}$ para indicar o grau de humificação de materiais orgânicos, pois esta última pode ser afetada seriamente pela presença de nitrogênio amoniacal [7].

O valor médio encontrado para este parâmetro foi de 202,1, indicando que o material analisado apresenta um grau de humificação maior que o encontrado no trabalho de 
Silva e colaboradores [7]. Na Figura 3 encontram-se as variações de $\mathrm{CO}$, NTK e relação $\mathrm{C} / \mathrm{N}$.

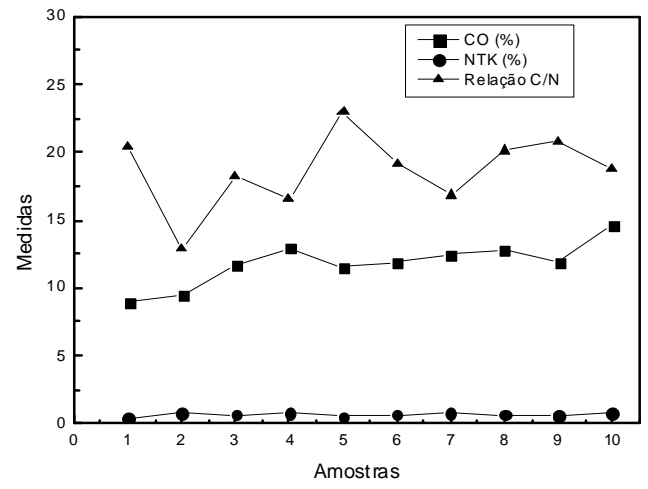

Figura 3. Variações de CO, NTK e relação C/N
Pela análise dos dados presentes na Figura 3 e Tabela 2, se observa que as variações na relação $\mathrm{C} / \mathrm{N}$ das várias amostras se devem as oscilações aleatórias das concentrações de CO e NTK.

\section{Potássio, fósforo e pH}

$\mathrm{Na}$ Tabela 3 estão as variações das concentrações de fósforo orgânico (PO), fósforo mineral (PM), potássio $(\mathrm{K})$ e os valores do $\mathrm{pH}$ com as respectivas médias e desvios padrões (DP).

Tabela 3. Valores de PO, PM, K e pH com as respectivas médias e desvios padrões.

\begin{tabular}{ccccccccccccc}
\hline & 1 & 2 & 3 & 4 & 5 & 6 & 7 & 8 & 9 & 10 & $\mathrm{M}$ & $\mathrm{DP}$ \\
$\mathrm{PO}\left(\mathrm{g} \mathrm{kg}^{-1}\right)$ & 0,15 & 0,17 & 0,15 & 0,22 & 0,13 & 0,0 & 0,0 & 0,02 & 0,04 & 0,12 & 0,1 & 0,08 \\
$\mathrm{PM}\left(\mathrm{g} \mathrm{kg}^{-1}\right)$ & 0,1 & 0,09 & 0,07 & 0,09 & 0,08 & 0,09 & 0,09 & 0,07 & 0,09 & 0,10 & 0,087 & 0,01 \\
$\mathrm{~K}\left(\mathrm{~g} \mathrm{~kg}^{-1}\right)$ & 0,90 & 0,80 & 0,68 & 0,8 & 0,76 & 0,76 & 0,52 & 0,68 & 0,76 & 0,94 & 0,76 & 0,12 \\
$\mathrm{pH}$ & 5,87 & 5,74 & 6,24 & 6,19 & 5,77 & 5,70 & 5,71 & 5,90 & 5,83 & 6,17 & 5,91 & 0,21 \\
\hline
\end{tabular}

$\mathrm{O} \mathrm{pH}$ de todas as amostras de lodo indicam que este material é levemente ácido. O valor médio foi de 5,91, ficando muito próximo aos encontrados em lodos resultantes de tratamento anaeróbico em que não é definido se o dispositivo utilizado é ou não um reator de manta de lodo $[23,24]$.

A concentração de potássio encontrada por fluorescência de raios X (Tabela 1) atingiu o valor de 2,2\% ou $22 \mathrm{~g} \mathrm{~K} \mathrm{~K}^{-1}$. Na Tabela 2 estão as concentrações deste elemento na forma em que ele é geralmente determinado, isto é, na forma trocável [32]. O extrator utilizado foi o de Mehlich, que é uma mistura de $\mathrm{HCl} 0,05 \mathrm{~N}$ e $\mathrm{H}_{2} \mathrm{SO}_{4}$ $0,025 \mathrm{~N}$ [17] e a concentração média deste elemento atingiu o valor de $0,76 \mathrm{~g} \mathrm{~kg}^{-1}$, valor este, menor que os encontrados em lodos resultantes de tratamento anaeróbico em que não é definido se o dispositivo utilizado é ou não um reator de manta de lodo [23, 24].

A concentração de fósforo encontrada por fluorescência de raios X (Tabela 1) atingiu o valor de 4,3\% ou $43 \mathrm{~g} \mathrm{Kg}^{-1}$. Para nenhum outro nutriente existem tantos trabalhos dedicados a métodos de extração como para o fósforo [32]. Na tabela 2 estão as concentrações deste elemento nas formas orgânica e mineral, extraídos segundo procedimento descrito por Jackson [18]. As concentrações médias atingiram valores 0,1 e $0,087 \quad \mathrm{~g}^{\mathrm{kg}^{-1}}$ respectivamente.

\section{Lixiviação de metais pesados}

Foi utilizado o método de Tessier [20]. Na contaminação ambiental, a exposição do material a determinadas condições permitem a formação de lixiviados, cujas concentrações de metais podem ser comparadas com as de efluentes que podem ser lançados, direto ou indiretamente nos cursos d'água. A Resolução CONAMA 430/11[12] traz os valores máximos permitidos (VMP) das condições padrões de lançamento de efluentes.

Quando os valores são encontrados acima do VMP, este percolado possui potencial para causar efeitos tóxicos ao ambiente. A Tabela 4 apresenta todos esses dados.

TABELA 04 - Concentrações médias de metais em $\mathrm{mg} \mathrm{L}^{-1}$ encontradas nas frações lixiviadas em $\mathrm{pH}=8,0$ e $\mathrm{pH}=5,0$; aplicação de um redutor (Red) e oxidante $(\mathrm{O})$; fração residual (R) e soma das frações (S) e o VMP de acordo com a Resolução CONAMA 430/11.

\begin{tabular}{cccccccc}
\hline & \multicolumn{7}{c}{ Frações $\mathrm{mg} \mathrm{L}^{-1}$} \\
\cline { 2 - 8 } & $\mathrm{pH}=8$ & $\mathrm{pH}=5$ & Red & \multicolumn{1}{c}{$\mathrm{O}$} & \multicolumn{1}{c}{$\mathrm{R}$} & $\mathrm{S}$ & \\
\hline $\mathrm{Cr}$ & 0,0 & 0,0 & 0,0 & 0,1 & \multicolumn{1}{c}{0,8} & \multicolumn{1}{c}{0,9} & 0,1 \\
$\mathrm{Cu}$ & 0,1 & 0,0 & 0,3 & 0,8 & 0,2 & 1,4 & 1,0 \\
$\mathrm{Ni}$ & 0,1 & 0,0 & 0,2 & 0,1 & 0,3 & 0,7 & 2,0 \\
$\mathrm{Ag}$ & 0,0 & 0,0 & 0,0 & 0,0 & 0,0 & 0,0 & 0,1 \\
$\mathrm{Fe}$ & 1,3 & 13, & 70,8 & 53,4 & 88,0 & 227,3 & 15 \\
$\mathrm{Mn}$ & 0,6 & 1,2 & 1,3 & 0,3 & 0,7 & 4,1 & 1,0 \\
$\mathrm{Zn}$ & 0,6 & 1,3 & 5,6 & 2,1 & 0,3 & 9,9 & 5,0 \\
$\mathrm{~Pb}$ & 0,0 & 0,0 & 0,2 & 0,2 & 0,1 & 0,5 & 0,5 \\
$\mathrm{Cd}$ & 0,0 & 0,0 & 12,3 & 1,0 & 203,2 & 216,2 & 0,2 \\
$\mathrm{Ba}$ & 0,1 & 0,0 & 0,8 & 0,5 & 1,6 & 3,0 & 5,0 \\
\hline
\end{tabular}


Analisando os dados presentes na Tabela 4, se observa que nos lixiviados as concentrações de cromo (residual), ferro (residual, e aplicação de oxidante e redutor), manganês (aplicação de um redutor e pH=5), zinco (aplicação de um redutor) e cádmio (residual e aplicação de oxidante e redutor) estão acima do VMP, segundo a Resolução CONAMA 430/11. Destas, a fração residual não é preocupante, pois a remoção dos metais só ocorre com a utilização dos ácidos fluorídrico e perclórico em ebulição, condições estas, indisponíveis no meio ambiente.

Maiores preocupações são justificadas em relação às frações lixiviadas em condições presentes no meio ambiente como, presença de oxidantes, redutores e $\mathrm{pH}$ igual a 5,0. Tais condições permitirão com que o ferro, manganês, zinco e cádmio sejam lixiviados em concentrações acima do VMP (CONAMA 430/11).

\section{Distribuição dos metais nas diversas frações}

A Figura 4 traz as distribuições das concentrações dos metais nas diversas frações.

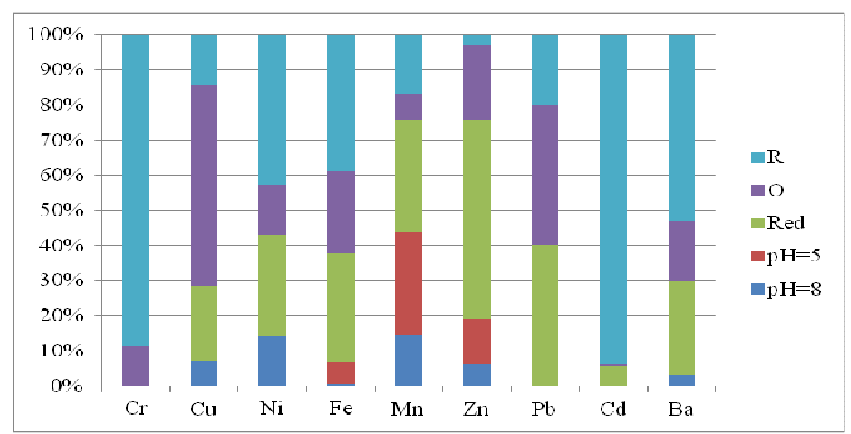

Figura 4: Distribuição das concentrações de cromo, cobre, níquel, ferro, manganês, zinco, chumbo, cádmio e bário nas frações lixiviadas em $\mathrm{pH}=8,0$ e pH=5,0; aplicação de um redutor (Red) e oxidante $(\mathrm{O})$ e fração residual $(\mathrm{R})$ nas amostras de lodo.

Pela análise dos dados presentes na Figura 4, se observa que o cromo está basicamente na fração residual. $\mathrm{O}$ cobre se concentra principalmente na fração lixiviável em presença de um oxidante. Para ferro, níquel e manganês e zinco predominam as frações residual e lixiviáveis em presença de redutor, oxidante e em $\mathrm{pH}$ igual a 5,0, mas zinco e manganês apresentam também uma concentração destacada na fração lixiviável em $\mathrm{pH}=8$. $\mathrm{O}$ chumbo e bário se concentram principalmente nas frações residual e lixiviadas em presença de oxidante e redutor. O cádmio está predominantemente na fração residual, mas se observa também certa fração lixiviável em presença de um redutor.

\section{Conclusões}

Através da fluorescência de raios $\mathrm{X}$, determinou-se que os elementos mais representativos são: $\mathrm{Al}, \mathrm{Si}, \mathrm{Fe}, \mathrm{S}, \mathrm{Ca}$, $\mathrm{P}$, Ti e K. A soma da média das concentrações destes atinge valores próximos de $99 \%$. Elementos como $\mathrm{Zn}, \mathrm{Mn}, \mathrm{Zr}, \mathrm{Cu}$, $\mathrm{V}, \mathrm{Cr}$ e $\mathrm{Ba}$ estão em concentrações muito baixas e em algumas amostras, estão ausentes. Dos elementos mais tóxicos, aqueles que foram encontrados através desta técnica foram: $\mathrm{Zn}, \mathrm{Cu}, \mathrm{Cr}$ e $\mathrm{Ba}$. A avaliação da lixiviação de determinados metais a partir do método de Tessier e a comparação com os VMP do CONAMA 430/11 demonstra riscos potenciais de lixiviação de ferro, manganês, zinco e cádmio em presença de redutor, ferro em presença de oxidante e manganês em $\mathrm{pH}$ igual a 5 . Todas as amostras de lodo apresentaram pH ácido. As concentrações de carbono orgânico, matéria orgânica, potássio NTK são inferiores e os da CTC são semelhantes àqueles encontrados em outros trabalhos. A relação CTC/CO é elevada, indica que o lodo analisado apresenta um grau de humificação, no mínimo, razoável.

\section{THE CHEMICAL STUDY OF SLUDGE GENERATED IN AN ANAEROBIC SYSTEM FOR TREATING RESIDENTIAL-SOURCED EFFLUENTS}

\section{ABSTRACT}

The treatment of residential-sourced effluents is usually done at Effluent Treatment Stations (ETS), through aerobic (or anaerobic) biological processes that feature devices of variable order, and generate residue that is defined as solid, according to ABNT 10004/2004. One of the devices that can be found in an ETS, one that utilizes the anaerobic process, is the sludge blanket reactor. The objective of this project was to chemically evaluate the composition of the sludge generated in one of these reactors, through the fluorescence of X-rays, organic carbon (OC), organic matter (OM), total Kjeldahl nitrogen $(\mathrm{TKN}), \mathrm{C} / \mathrm{N}$ relation, effective cation exchange capacity (ECEC), ECEC/OC relation, potassium $(\mathrm{K})$, organic phosphorus (OP), mineral phosphorus (MP), and determining the concentration of $\mathrm{Cr}, \mathrm{Cu}, \mathrm{Ni}, \mathrm{Ag}, \mathrm{Fe}$, $\mathrm{Mn}, \mathrm{Zn}, \mathrm{Pb}, \mathrm{Cd}$, and $\mathrm{Ba}$ in the extracts obtained through the Tessier method. Through the fluorescence of X-rays, it was possible to observe that the sum of the percentages for the elements $\mathrm{Al}, \mathrm{Si}, \mathrm{Fe}, \mathrm{S}, \mathrm{Ca}, \mathrm{P}, \mathrm{Ti}, \mathrm{K}$, and $\mathrm{Zn}$ was close to $99 \%$. Also, the average values for OM, TKN and ECEC were, respectively, 20.2\%, $0.64 \%$, and 19.6 cmolc $\mathrm{kg}^{-1}$. Lastly, the disposal of this material in the environment can be associated to a certain risk, due to the concentration of iron, manganese, zinc, and cadmium, along with a reducer; iron in the presence of an oxidant; and manganese in the presence of $\mathrm{pH}=5$, being above the maximum allowed value of the CONAMA 430/11 resolution.

Keywords: sludge from effluents; lixiviation of metals.

\section{Referências}

[1] GUIMARAES, J. R.; NOUR, E. A. A.; Tratando nossos esgotos: processos que imitam a natureza, Cadernos Temáticos de Química Nova na Escola, Vol. 1, p. 19-30, 2001

[2] METCALF \& EDDY; Wastwater, Engeneering: Treatment Disposal and Reuse 3 ed.; Mcgraw Hill; New York, 1991. 1344p.

[3] CHERNICHARO, C. A. L.; Pós tratamento de efluentes de reatores anaeróbios. Princípios do tratamento biológico de águas residuárias; SEGRAC Editora e Gráfica; Belo Horizonte, 2001. 544p. 
[4] SANTOS, M. de L. F. dos; Tratamento e Utilização de Esgotos Sanitários; SERMOGRAF Artes Gráficas e Editora Ltda; Rio de Janeiro, 2006. 403p

[5] VAN HAANDEL, A. C.; LETTINGA, G.; Tratamento Anaeróbio de Esgotos, um manual para regiões de clima quente; Epgraf; Campina Grande/PB, 1994. 240p.

[6] CHERNICHARO, C.A.L.; Reatores Anaeróbios; Departamento de Engenharia Sanitária e Ambiental - UFMG; Minas Gerais, 1997. 245p.

[7] SILVA, P. R. D.; LANDGRAF, M. D.; RESENDE, M. O. O.; Acompanhamento químico da vermicompostagem de logo de esgoto doméstico, Química Nova, Vol. 34, n. 6, p. 956-961, 2011

[8] NASCIMENTO, C.W.A.; BARROS, D.A.S.; MELO, E.E.C.; OLIVEIRA, A.B.; Alterações químicas em solos e crescimento de milho e feijoeiro após aplicação de lodo de esgoto, R. Bras. Ci. Solo, Vol. 28, p. 385-392, 2004

[9] MERLINO, L.C.S.; MELO, W.J.de.; MACEDO, F.G.de.; PERASSOLO, A.C.T.; RIBEIRO, M.H.; MELO, G.M.P.de.; Bário, cádmio, cromo e chumbo em latossolo após onze aplicações anuais de lodo de esgoto. R. Bras. Ci. Solo. Vol. 34, p. 2031-2039, 2010.

[10] VIEIRA, R.F.; TANAKA, R.R.; TSAI, M.S.; PÉREZ, D.V.; SILVA, C.M.M.deS. Disponibilidade de nutrientes no solo, qualidade de grãos e produtividade de soja em solo adubado com lodo de esgoto. Pesq. agropec. bras. Vol..40, n. 9, p. 919-926, 2005.

[11] CHIBA, M.K.; MATTIAZZO, M.E.; OLIVEIRA, F.C.; Cultivo de cana-de-açúcar em argissolo tratado com lodo de esgoto. Fertilidade do solo e nutrição da planta. R. Bras. Ci. Solo, Vol. 32, p. 653-662, 2008

[12] Resoluções CONAMA, 430/2011. Disponível em: <http://www.mma.gov.br/port/conama/legiabre.cfm?codlegi=646. Acesso em: 15 de ago. 2012.

[13] KIEHL, E. J.; Fertilizantes Orgânicos, Editora Agronômica Ceres; São Paulo, 1985. 492p

[14] LUCHESE, E.B.; FAVERO, L.O.B.; LENZI, E.; Fundamentos da Química do Solo, Teórica e Prática, Frutas Bastos; Rio de Janeiro, 2001. $182 \mathrm{p}$.

[15] MELLO, F. A. F. de; BRASIL SOBRINHO, M.O C.; ARZOLLA, S.; SILVEIRA, R.I.; COBRA NETTO, A.; KIHEL, J.C.; Fertilidade do solo 3ed., Nobel; Piracicaba, 1988. 400p.

[16] COTTA, J.A.O.; REZENDE, M.O.; PIOVANI, M.R.; Avaliação do teor de metais em Sedimento do Rio Betari no Parque Estadual Turístico do Alto Ribeira - Petar, São Paulo, Brasil, Química Nova, Vol. 19, n. 1, p. 4045,2006

[17] RAIJ, B. Van.; FEITOSA, C.T.; SILVA, N.M. da.; Comparação de quatro extratores de fósforo de solos, Bragantia, Vol. .43, n. 1, p. 17-29, 1984.

[18] JACKSON, M. L.; Análisis Químico de Suelos, Ediciones Omega S. A.; Barcelona, 1964. 662p.

[19] PAVAN, M.A.; BLOCH, M.F.; ZEMPULSKI, H.D.; MIYAZAWA, M.; ZOCOLER, D.C.; Manual de Análise Química de Solo e Controle de Qualidade; IAPAR; Londrina, 1992.40p.

[20] TESSIER, A.; CAMPBELl, P. G. C.; BISSON, M.; Sequential extraction procedure for the speciation of particulate trace metals, Analitical Chemistry, Vol. 51, p. 844-851, 1979.

[21] Lã, R.; BARRA, C.M.; Avaliação dos métodos de extração sequencial de Tessier, Keller e Miller na determinação de ferro nativo em três tipos de solos: orgânico, Brunizem e Latossolo, Química Nova, Vol. 26, n. 3, p. 323330, 2003.
[22] BOSSO, S.T.; ENZWEILER, J.; Ensaios para determinar a (bio) disponibilidade de chumbo em solos contaminados: revisão, Química Nova, Vol. 31, n. 2, p. 394-400, 2008.

[23] BAIRD, C.; Química Ambiental; Bookman; Porto Alegre/RS, 2002, $622 \mathrm{p}$.

[24] SIMONETE, M. A.; KIEHL, K. de C.; Extração e fitodisponibilidade de metais em resposta a adição de lodo de esgoto no solo, Scientia Agrícola, Vol.39, n. 3, p. 555-563, 2002.

[25] GOMES, S. B. V.; NASCIMENTO, C. W. A. do.; BIONDI, C. M.; ACCIOLY, M. de A.; Distribuição de metais pesados em plantas de milho cultivadas em argissolo tratado do lodo de esgoto, Ciência Rural, Vol. 36, n. 6 , p.1689-1695, 2006

[26] BOEIRA, R.C; SOUZA, M.D. de.; Estoques de carbono orgânico e de nitrogênio, $\mathrm{pH}$ e densidade de um latossolo após três aplicações de lodo de esgoto, R. Bras. Ci. Solo. Vol. 31, p. 581-590, 2007.

[27] MORENO, M. I. C.; SCHIAVINI, I.; Relação entre vegetação e solo em um gradiente florestal na Estação Ecológica do Panga, Uberlândia (MG), Revta brasil. Bot., Vol. 24, n. 4, p. 537-544, 2001.

[28] LAMIN, S. S. M.; JORDÃO, C. P.; BRUNE, W., PEREIRA, J. L.; BELATTO, D. R..; Caracterização química de vermicomposto e avaliação de sua capacidade de absorver zinco, Química Nova, Vol. 21, n. 3, p. 278 283,1998

[29] RAIJ, B.V.; Recomendações de adubação e calagem para o Estado de São Paulo - Boletim técnico no 1, Fundação IAC; Campinas, 1996.

[30] MENDHAM, J.; DENNEY, R.C.; BARNES, J.D.; THOMAS, M.J.K. Vogel: Análise Química Quantitativa, Editora LTC, Rio de Janeiro/RJ, 2002. 462p.

[31] DIAS, B. de O.; SILVA, C. A.; SOARES, E. M. B.; BETTIOL, W.; Estoque de carbono e quantificação de substâncias húmicas em latossolo submetido a aplicação contínua de esgoto, R. Bras. Ci. Solo, Vol. 31, p. 701-711, 2007

[32] RAIJ, B.V.; Fertilidade do solo e manejo de nutrientes, ESALQ/USP, Piracicaba, 2011, 420p 